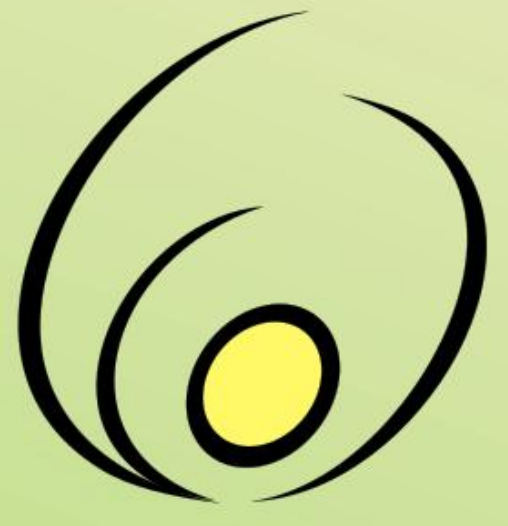

Fórum de

Pró-Reitores

de Extensão

das Instituições

Públicas de

\section{Educação Superior}

\section{Brasileiras}

Revista Brasileira de Extensão Universitária

v. 7, n. 2, p. 139-144 jul.- dez. 2016 e-ISSN 2358-0399

aceito para publicação em 19 de agosto de 2016

\title{
A extensão universitária e a ludicidade na educação infantil contra crueldade animal e violência interpessoal
}

\author{
Daniel Cortes Beretta ${ }^{1}$, \\ Juciene Silva Oliveira $^{2}$, Daniela Costa Vilela ${ }^{2}$
}

Resumo: A crueldade contra animais coexiste habitualmente com uma vasta gama de outros problemas (violência interpessoal, comportamento anti-social, bullying, etc.) e pode ser identificada em crianças com idade inferior aos sete anos. A violência contra animais reflete diretamente na violência doméstica e interpessoal, a crueldade contra seres indefesos e emocionalmente dependentes é parte de um ciclo insidioso de agressão. A formação de consciência crítica e individual se faz necessária nas etapas iniciais de vida do ser humano, portanto deve-se reconhecer e assumir que a criança é um ser social que constrói e cria cultura. O uso do lúdico através de jogos, teatros e brinquedos, é instrumento eficaz no desenvolvimento do pensamento e da autonomia infantil. Por isso, objetivou-se, através da ludicidade, que o público infantil aprendesse e transmitisse de forma adequada e segura, que os animais têm sentimentos; e que atos de crueldades contra eles não devem ser feitos ou repetidos. As atividades foram desenvolvidas de agosto de 2014 a novembro de 2015, nas cidades de Mineiros e Jataí, Goiás, Brasil. Foram realizadas ações pedagógicas aplicadas, como teatro, cantiga, cartilha educativa, brincadeiras interativas com massa de modelar e quebra-cabeça. Com a realização do projeto notou-se o interesse das crianças em aprender, transmitir a mensagem a seus familiares e, principalmente, colocar em prática o conhecimento adquirido por meio da dinâmica realizada. Como retorno, observou-se que a maneira lúdica e educativa foi eficiente em despertar o interesse das crianças contra a crueldade animal, quebrando neste caso o ciclo insidioso de violência.

Palavras-chave: Extensão Universitária, Bem Estar Animal, Sensibilização, Ensino Fundamental.

\footnotetext{
${ }^{1}$ Professor Adjunto, Centro Universitário de Mineiros (UNIFIMES), Brasil. berettadc@hotmail.com (autor para correspondência)

${ }^{2}$ Discentes do Curso de Medicina Veterinária, Centro Universitário de Mineiros (UNIFIMES), Brasil. juciene.juh@gmail.com
} 


\title{
The university extension and ludicity in early childhood education against animal cruelty and interpersonal violence
}

\begin{abstract}
Animal cruelty usually coexists with other problems (interpersonal violence, anti-social behavior, bullying, etc.) and it can be identified before the age of seven years. Criticism and individual conscience formation becomes necessary in the early stages of human life, and therefore, it must be recognized and assumed that the child is a social being who builds and creates culture. The use of the ludic activities such as games, theater and toys is an efficient instrument for the development of children's autonomy and cognitive skills. Thus, this project aimed at through ludicity promoting the awareness that animals have feelings and that acts of cruelty against them should not be made or repeated. The activities were carried out from August 2014 to November 2015 in the cities of Mineiros and Jataí, Goiás State, Brazil. Pedagogical actions such as theater, singing, educational spelling book, interactive play with modeling clay and puzzle were used as a resource for this initiative. After the project ended the children's interest in learning and transmitting the message to their families could be observed, and especially their desire to put into practice the knowledge acquired throughout the activities. In return, education through ludicity was observed and showed to be effective in fostering the interest of children against animal cruelty and breaking the insidious cycle of violence.
\end{abstract}

Key-words: University Extension, Animal Welfare, Raising Awareness, Elementary School.

\section{La extensión universitaria y lo lúdico en la educación infantil contra la crueldad animal y la} violencia interpersonal

Resumen: La crueldad animal suele coexistir con otros problemas (violencia interpersonal, comportamiento antisocial, acoso, etc.) y pueden ser identificados antes de la edad de siete años. La crítica y la formación de la conciencia individual se hace necesaria en las primeras etapas de la vida humana. Por lo tanto, debe-se reconocer y presuponer que el niño es un ser social que construye y crea cultura. El uso de las actividades lúdicas a través de juegos, teatro y juguetes es un instrumento eficaz para el desarrollo del pensamiento y la autonomía de los niños. Por lo tanto, el objetivo fue, a través de la ludicidad, que los niños aprenderán y transmitan correctamente y con seguridad que los animales tienen sentimientos y que los actos de crueldad contra ellos no deben hacerse o repetirse. Se realizaron las actividades de agosto 2014 a noviembre 2015 en las ciudades de Mineiros y Jataí, Estado de Goiás, Brasil. Acciones pedagógicas como el teatro, canción, libro de lectura educativa, juego interactivo con plastilina y el rompecabezas fueran utilizadas. Después de la finalización del proyecto se observó el interés de los niños en el aprendizaje y en transmitir el mensaje a sus familias, y sobre todo para poner en práctica los conocimientos adquiridos en las dinámicas realizadas. Además, se observó como resultado que la educación a través ludicidad fue eficaz en despertar el interés de los niños contra la crueldad animal, rompiendo en este caso el ciclo insidioso de la violencia.

Palabras-clave: Extension Universitária, Bienestar de los Animales, Sensibilización, Escuela Primaria.

\section{Introdução}

A crueldade contra animais coexiste habitualmente com uma vasta gama de outros problemas (violência interpessoal, comportamento anti-social, bullying, etc.) e pode ser identificada, em certos indivíduos, antes dos sete anos de idade (FONSECA; DIAS, 2011). Crianças na faixa etária de três aos oito anos podem apresentar sintomas de transtorno da conduta: uma enfermidade psicológica que pode se manifestar inicialmente através de maus tratos aos animais. Esse desvio de conduta carece de ações preventivas e em conjunto com pais e professores (BORDIN; OFFORD, 2000). A violência contra animais reflete diretamente na violência doméstica e interpessoal; a crueldade contra seres indefesos e emocionalmente dependentes é parte de um ciclo insidioso de agressão (MERZ-PEREZ; HEIDE, 2004). O modelo proposto mais usado e conhecido para explicar esse fenômeno, é o da passagem progressiva da crueldade contra animais na infância para a violência interpessoal na idade adulta (graduation hypothesis). Nesse modelo, o indivíduo, ao presenciar ou mesmo realizar agressões contra animais, passa a perder gradativamente a sensibilidade ao sofrimento desses seres vivos. A perda do respeito pela vida e a evolução/aprendizagem do processo cruel contra animais de estimação, faz com que, posteriormente, a agressão seja orientada para criaturas inferiores, indefesas ou mais fáceis de controlar, primeiro no seio familiar e depois fora de casa (WRIGHT; HENSLEY, 2003).

A formação de uma consciência crítica e individual é necessária desde as primeiras etapas de vida do ser humano. Assim, deve-se reconhecer e assumir que a criança é um ser social que constrói e cria cultura. A construção do conhecimento refere-se a movimento ambíguo de transformação, quando adultos e crianças, constituindo elementos contrários e complementares, 
reapropriam-se da atividade lúdica, criando e produzindo novos conhecimentos através de brincadeiras (PRADO, 1999). As brincadeiras pressupõem uma aprendizagem sócio-cultural, pois além de construir e reconstruir conhecimentos, as atividades lúdicas e artísticas tornam os encontros mais interessantes, dinâmicos e criativos (BEHLING; ISLAS, 2014). Participando da brincadeira a criança experimenta, descobre, inventa, aprende e aprimora seus conhecimentos. Nesta fase, já pode ser formado um conceito de vida, facilitando e transmitindo a aprendizagem para a família, amigos e vizinhos.

Por isso objetivou-se através da ludicidade que o público infantil aprendesse e transmitisse, de forma adequada e segura, que os animais têm sentimentos, dores, alegrias e direitos; e que atos de crueldades contra eles não devem ser feitos ou repetidos.

\section{Material e Métodos}

As atividades do Projeto de Extensão "Não Atire o Pau no Gato" foram desenvolvidas de agosto de 2014 a novembro de 2015, nas cidades de Mineiros e Jataí, Goiás, Brasil. Foi realizado um estudo descritivo das ações pedagógicas aplicadas. As ações incluíram atividades como teatro, cantiga, cartilha educativa, brincadeiras interativas com massa de modelar e quebracabeça. Para as atividades descritas foi realizado um contato preliminar com as escolas para verificar interesse de participação no projeto. A partir daí foram mapeadas as turmas que se enquadravam na faixa etária pretendida e as atividades foram realizadas em consonância com as respectivas idades. $\mathrm{O}$ projeto atendeu às faixas etárias mais baixas do público-alvo (3-7 anos), composta, principalmente, por alunos da educação infantil e primeiros anos do ensino fundamental. Os dados apresentados neste estudo foram obtidos por diálogo questionado, observação e interação entre os monitores, professores e as crianças.

As escolas públicas e particulares que oferecem ensino fundamental e infantil do município de Mineiros foram convidadas a participarem do projeto realizado durante a semana acadêmica do Centro Universitário de Mineiros (UNIFIMES), que tem como um de seus objetivos, promover a interação da comunidade e estudantes com programas na área de extensão, ensino, pesquisa e ação comunitária, visando o fortalecimento dos vínculos com a sociedade atual. $\mathrm{O}$ evento ocorre anualmente no mês de outubro e o projeto foi apresentado durante dois anos seguidos, 2014 e 2015, atendendo um total de seis escolas.

Na cidade de Jataí houve o contato prévio de uma instituição particular que oferece ensino médio, fundamental e infantil, para que fosse realizada a ação de extensão do projeto. O convite veio para fortalecer, de maneira lúdica e aplicada, a atividade disponível no material didático da escola sobre "cuidados e maus tratos animal".

Além das escolas, os alunos fizeram a divulgação do projeto em praças e em um shopping, e atenderam a um público infantil de várias regiões da cidade. Os discentes desenvolveram uma logomarca e um mascote para o projeto, e utilizaram essas imagens na confecção de camisetas e materiais didáticos (Figura 1).

No teatro, as fantasias foram criadas pela equipe do projeto de forma artesanal, com material de tecido não tecido (TNT), folhas de Espuma Vinílica Acetinada (EVA) coloridas e maquiagem. O teatro educativo, elaborado pelos discentes, foi narrado por dois palhaços que interagiam com as crianças, estimulando as respostas participativas das mesmas. A estória relatou a vida de um cão que era maltratado pelo seu dono, e que depois de abandonado passa a ser cuidado por um proprietário mais consciente. Em certo momento, os dois proprietários se encontram e após o cão ser agredido pelo antigo dono, um xerife é chamado para orientar as ações erradas do mesmo, ensinando que "aquilo não pode ser feito". Dentro do contexto foram abordadas as cinco liberdades dos animais, sendo: "Ser livres de medo e estresse", "Ser livres de fome e sede", "Ser livres de desconforto", "Ser livres de dor e doenças" e "Ter liberdade para expressar seu comportamento ambiental" (FARM ANIMAL WELFARE COUNCIL,, 1992). Como complemento ao teatro houve a cantiga popular infantil de caráter ético "Não atire o pau no gato": "Não atire o pau no gato (toto), porque isso (sso-sso), não se faz (faz-faz), ô gatinho (nho-nho), é nosso amigo (go-go), não devemos maltratar os animais, jamais!". Toda a apresentação teve duração de aproximadamente 20 minutos (Figura 2).

A cartilha foi desenvolvida pelos participantes do projeto, é de colorir e retrata situações de bem-estar e maus tratos, com o intuito de ensinar às crianças a forma correta de como os animais devem ser tratados. Os discentes envolvidos no projeto também desenvolveram a figura de um mascote, que ilustra as cartilhas e ajuda as crianças a humanizarem as situações. Durante a pintura da cartilha os monitores acompanharam as crianças, ensinando e reforçando o que foi aprendido no teatro.

Posteriormente, foram realizadas brincadeiras interativas com massa de modelar, em que as crianças representam os animais de estimação. Montagem de quebra-cabeça com quatro partes, feitos com EVA e figuras de animais de espécies variadas. E por fim, todas as crianças ganharam uma insígnia de xerife protetor dos animais e sacolinhas de lixo para carros com mensagens educativas e logomarca do projeto.
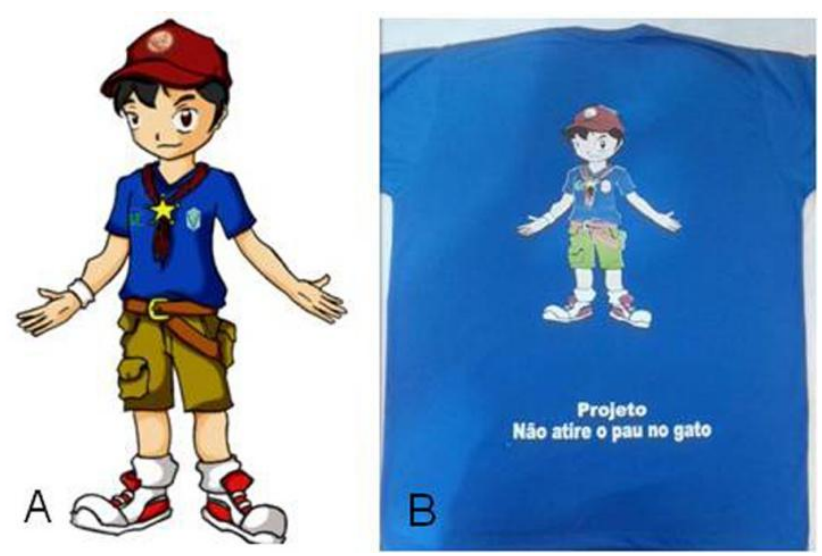

Figura 1. logomarca e um mascote do projeto. 

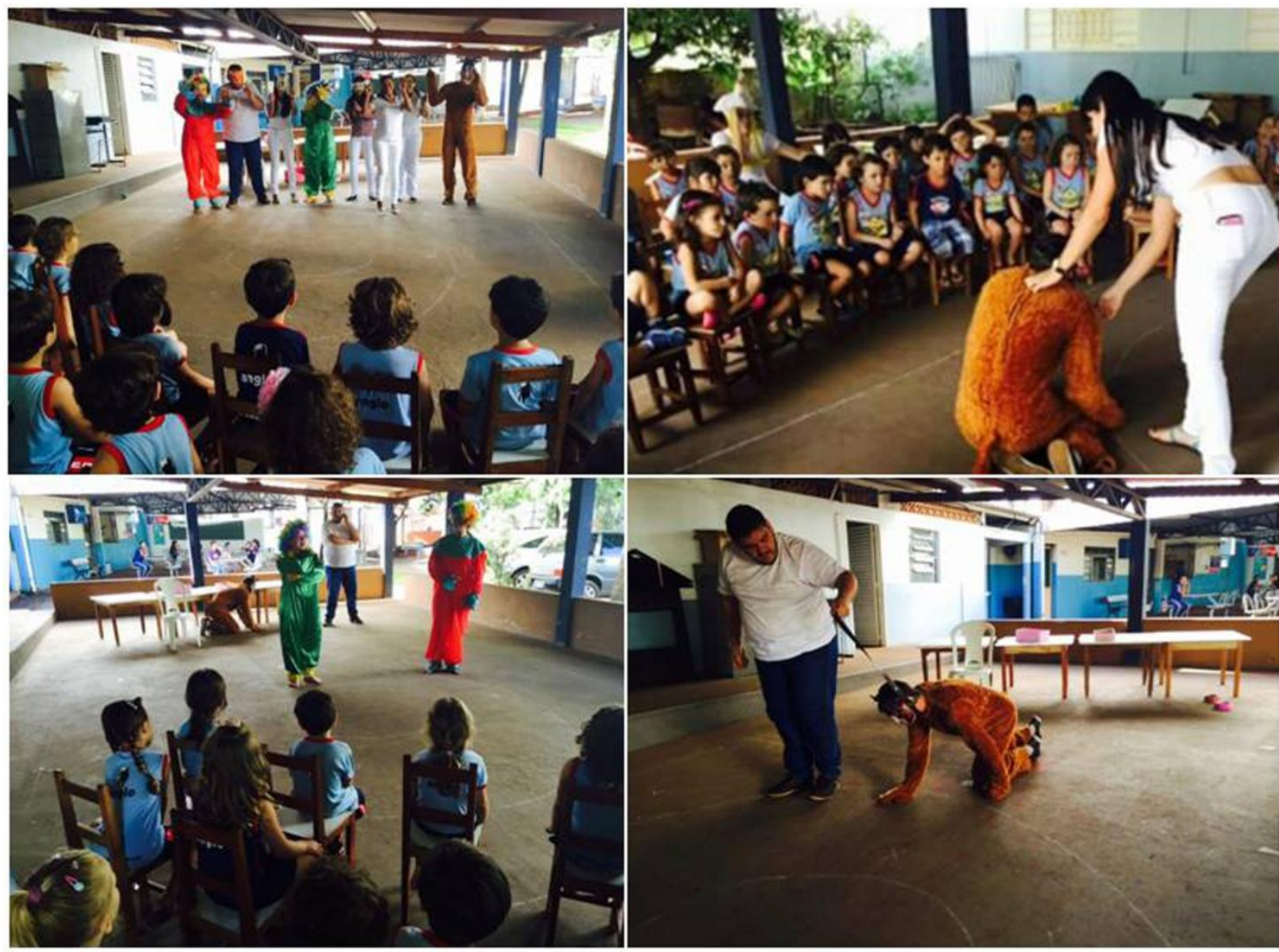

Figura 2. Atividades teatrais com alunos do ensino fundamental.

\section{Resultados e Discussão}

O projeto foi desenvolvido com aproximadamente 200 crianças nas cidades de Jataí e Mineiros, Goiás, Brasil. A apresentação foi realizada com ampla variação das técnicas de ensino (cartilha, teatro, cantiga, modelagem e quebra cabeças). Segundo Cruz (1999), deve-se dar ao educando, além de variedades, maior número de experiências, proporcionando a possibilidade de compreender a dinâmica interpessoal de respeito pelos direitos próprios e alheios.

Os dois municípios onde o projeto foi desenvolvido são caracterizados por variáveis de natureza cultural. Parte das crianças é proveniente ou frequenta as zonas rurais, e presenciam com alguma regularidade à matança de animais domésticos ou selvagens para consumo da família. Alem disso, a captura e domesticação de animais silvestres são hábitos culturais comuns nessas regiões. Durante o projeto foi necessário educar considerando as diversidades culturais. O que em um meio ou cultura é normal, em outro pode ser considerado barbárie ou crime. Por isso, a educação lúdica auxiliou na mudança cultural provocada. Para Fernandes (2005) na mudança cultural provocada, o conteúdo intencional adere a um horizonte cultural que confere aos agentes humanos a possibilidade de escolher fins alternativos ou exclusivos e de pô-los em prática, através de meios que assegurem, no mínimo, controle racional do desencadeamento e das principais fases do processo.

Os personagens animais do projeto foram escolhidos para expor a realidade vivenciada pelos alunos. O cão, retratado no teatro, e o gato, retratado na cantiga; são animais domésticos que convivem no mesmo ambiente familiar que as crianças, e com os quais a maioria tem um relacionamento afetivo/dependente. Segundo o modelo da passagem progressiva da crueldade contra animais na infância para a violência interpessoal no adulto (graduation hypothesis). A violência contra seres vivos com os quais as crianças possuem maior convivência e carinho facilita a evolução do processo para voltar-se, posteriormente, a vítimas inferiores indefesas ou mais fáceis de controlar, como familiares e outros coleguinhas (bullying) (WRIGHT; HENSLEY, 2003). No presente trabalho, objetivou-se educar no sentido de prevenir esses atos e evitar o ciclo insidioso de violência inter-pessoal.

No teatro, o personagem "animal" foi caracterizado como o cachorro. Além do cão como personagem, havia dois palhaços, o Tico e o Teco; o dono do cachorro, que o maltratava; a protetora dos animais e o xerife, que tem o papel de educador, ensinando a forma correta de tratar 
os animais. De maneira recorrente e incisiva, todas as crianças recriminaram a atitude negativa do dono e defenderam o cachorro. Com o desenrolar da estória o dono foi repreendido pelo xerife e a protetora dos animais adotou o cão maltratado. Assim, as crianças interagiram e compartilharam as opiniões durante 0 teatro. Segundo Vigotski (1991), quando uma criança age em conjunto a um momento de ação imaginária, o seu comportamento é dirigido além da percepção ou da situação imediata, e ela consegue também agir pelo significado de toda a situação. O teatro, embora colocasse as crianças no mundo imaginário, tratava da questão preocupante e real. Assim, prestando atenção na estória, os alunos foram levados à sensibilização frente a um problema muito sério, sendo convidados a colaborar como agentes multiplicadores da mensagem (BEHLING; ISLAS, 2014).

A cantiga de roda "Não atire o pau no gato" é uma versão modificada da cantiga "Atirei o pau no gato", e foi apresentada às crianças que interagiram de maneira lúdico-participativa, associando a musica ao teatro recém-assistido. As cantigas de roda não têm sua autoria identificada e são continuamente modificadas, adaptando-se à realidade do grupo de pessoas que as cantam. Em alguns locais do país observa-se um fenômeno de apropriação das cantigas, porém, com um caráter próprio (CASCUDO, 2001). Essa atividade favorece as inter-relações pessoais e o desenvolvimento de um sentido de grupo e de uma identidade cultural (AYOUB, 2000). No projeto, o uso da cantiga objetivou modificar a identidade cultural dos maus tratos e inserir uma nova cultura, a dos cuidados com os animais. A linguagem musical é um excelente meio para o desenvolvimento da expressão, do equilíbrio, da autoestima e do autoconhecimento, além de poderoso meio de integração social (BRITO, 2005).

A arara canindé (Ara ararauna) retratada na cartilha e no quebra-cabeças, é uma das espécies emblemáticas do cerrado brasileiro, frequentemente encontrada em ambientes rurais e urbanos dos municípios onde o projeto foi desenvolvido. Sua população vem diminuindo gradativamente pela destruição do habitat e pelo tráfico/comércio ilegal para colecionadores particulares, zoológicos, e pet shops. A arara canindé é procurada como animal de estimação por sua docilidade em cativeiro e grande beleza. Além da captura, depósito e transporte, os animais apreendidos também sofrem maus tratos como falta de água, alimentos, restrição de espaço e mutilações, podendo vir a óbito. Para o processo educativo, é de fundamental importância que os indivíduos se identifiquem como parte do meio ambiente, estando concentrados nas situações ambientais do seu entorno local, dentro da perspectiva histórica, percebendo as causas reais dos problemas e, assim, agindo efetivamente para sua transformação (BEHLING; ISLAS, 2014).

$\mathrm{Na}$ cartilha a arara Canindé foi representada livre e aprisionada, a criança deveria identificar a maneira certa ou errada de vida desse animal. $\mathrm{O}$ auxílio dos monitores nessa etapa reforçou o aprendizado (Figura 3). Nesse contexto, observou-se a falta de informação dos alunos, tendo em vista que muitos escolheram a situação de maus tratos, acreditando que se tratava do jeito correto de cuidar de seus animais. Possivelmente, essas crianças estavam apenas recriando o que haviam absorvido de informação vivenciada por elas. Segundo Nolte e Harris (2011), as crianças aprendem o tempo todo com os pais, talvez não o que dizem, mas sim o que os vêem fazendo. São os primeiros e mais importantes exemplos a seguir. Os pais podem ensinar certos valores, mas elas absorverão aquilo que é transmitido pelo comportamento, sentimentos e atitudes na vida diária, sendo esse modelo lembrado por toda a vida.

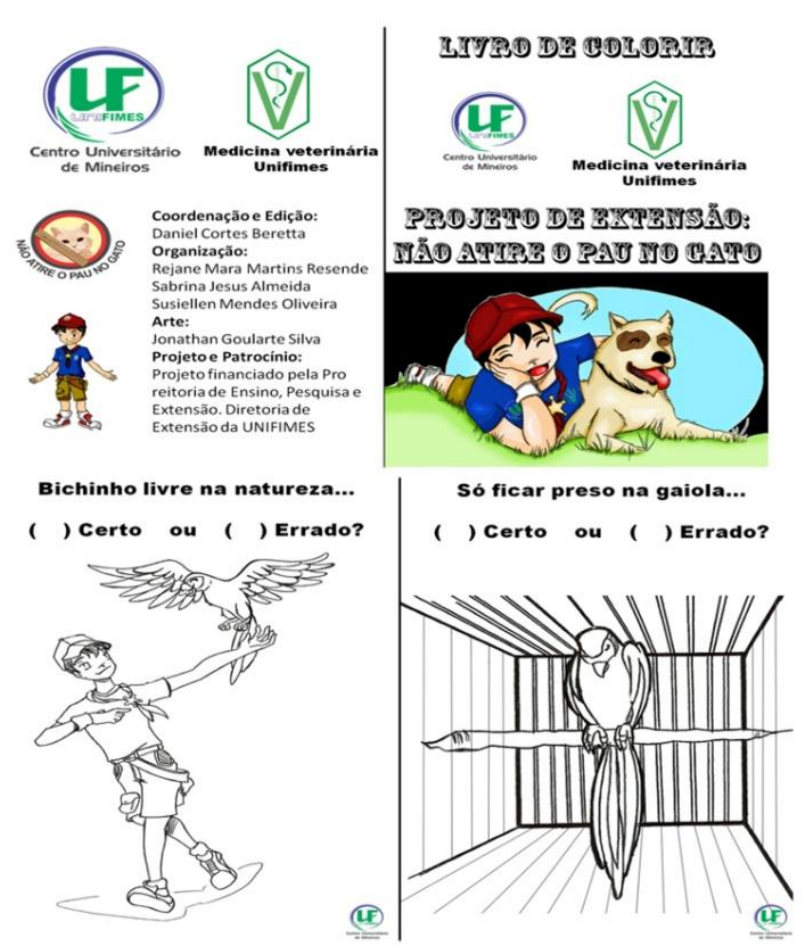

Figura 3. Cartilha didática utilizada no projeto.

Todas as crianças ganharam uma insígnia de xerife protetor dos animais e sacolinhas de lixo para carros com mensagens educativas e logomarca do projeto (Figura 4). A insígnia de protetor teve como intuito motivar a criança a ser um modelo de proteção aos animais, a se destacar dentro do seu grupo familiar, enquanto a sacolinha com mensagens educativas foi utilizada como instrumento fornecido à criança para agir como agente de transformação no seu meio familiar e social. Cada indivíduo se torna motivado por suas causas próprias, quem educa deve direcionar e projetar o conhecimento no intuito de despertar a necessidade das causas e do agir em grupo. O processo motivacional é um estado de desconforto, que se inicia no surgimento de uma necessidade e direciona o indivíduo a alguma ação (KNAPIK, 2005). A escola deve habilitar os alunos para se tornarem agentes multiplicadores de transformação, capacitando-os para desenvolver habilidades sociais e para a resolução de problemas (CRUZ, 1999).

Durante a aplicação das ações dentro do projeto (teatro, cantiga, cartilha educativa, brincadeiras interativas com massa de modelar e quebra-cabeça), foi observado pelos alunos/monitores e professores que acompanhavam as 
crianças, um gradativo aprendizado entre as atividades lúdicas. Os alunos relatavam, comentavam e associavam aquilo que 'pode' ou 'não pode' ser feito. Ao final, as crianças entregavam as sacolinhas de lixo personalizadas aos pais e saiam expondo o que aprenderam nas brincadeiras.
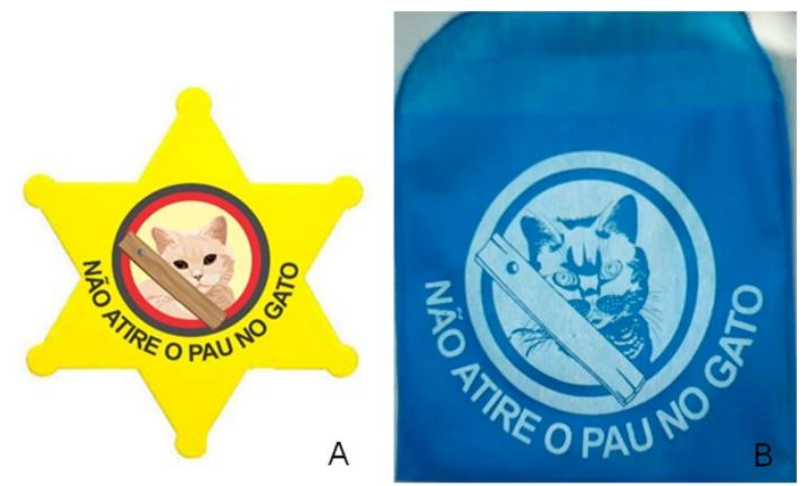

Figura 4. Insígnia de xerife protetor dos animais e sacolinhas de lixo para carros com mensagens educativas e logomarca do projeto.

\section{Conclusões}

Observou-se o interesse das crianças em aprender, transmitir e colocar em prática junto a seus familiares o conhecimento adquirido por meio da dinâmica do projeto "Não atire o pau no gato". A maneira lúdica e educativa foi eficiente em despertar o interesse das crianças contra a crueldade animal, quebrando neste caso, o ciclo insidioso de violência.

Outro fator a ser destacado foi o reflexo dessa atividade de extensão na formação dos alunos universitários envolvidos que, da mesma maneira que as crianças, também se tornaram agentes multiplicadores de transformação social, para docentes, discentes e funcionários da Universidade.

\section{Agradecimentos}

Agradecemos a todos os alunos participantes do projeto "Não atire o pau no gato" e ao Centro Universitário de Mineiros, Pró-Reitoria de Ensino, Pesquisa e Extensão e a Diretoria de Extensão da UNIFIMES pelo financiamento do Projeto.

\section{Referências}

AYOUB, E. Brincando com o ritmo na Educação Física. Revista Presença Pedagógica, v.6, n.34, p.49-57, 2000.

BEHLING, G. M.; ISLAS, C. A. Extensão universitária, educação ambiental e ludicidade na preservação de animais silvestres. Revista Conexão UEPG, v. 10, n.1, p.128-138, 2014.

BRITO, T. A. Música na educação infantil: propostas para a formação integral da criança. São Paulo, Brasil: Peiropólis, 2005.

CASCUDO, L. C. Dicionário do folclore brasileiro. São Paulo: Global, 2001.

CRUZ, M. N. Refletindo sobre as cantigas de roda. Rio de Janeiro: O portão das letras, 1999.

FARM ANIMAL WELFARE COUNCIL, Updates the five freedoms. Veterinary Record, v. 17, p. 357, 1992.

KNAPIK, J. Administração geral e de recursos humanos. Curitiba, Brasil: IBPEX, 2005.

NOLTE, D. L; HARRIS, R. As Crianças aprendem o que vivenciam. Tradução de Maria Luiza Newlands da Silveira, Rio de Janeiro, Brasil: Sextante, 2011.

PRADO, C. D. As crianças pequenininhas produzem cultura? Considerações sobre educação e cultura infantil em creche. Pró-Posições, v.10, n.1, p.115, 1999.

VIGOSTKI, L. S. A formação social da mente - o desenvolvimento dos processos psicológicos superiores. São Paulo, Brasil: Livraria Martins Fontes Editora, 1998.

WRIGHT, J.; HENSLEY, C. From animal cruelty to serial murder: applying the graduation hypothesis. International Journal of Offender Therapy and Comparative Criminology, v. 47, n. 1, p. 71-88, 2003.

$$
* * *
$$

Como citar este artigo:

BERETTA, D. C.; OLIVEIRA, J. S.; VILELA, D. C. A extensão universitária e a ludicidade na educação infantil contra crueldade animal e violência interpessoal Revista Brasileira de Extensão Universitária, v. 7, n. 2, p. 139-144, 2016. Disponível em: <https://periodicos.uffs.edu.br/index.php/ $\underline{\text { RBEU/article/view/3114/pdf }>}$ 